\title{
Body composition, somatotype and risk of premenopausal breast cancer: a case-control study in Uruguay
}

Ronco $\mathrm{AL}^{1,2, *}$, De Stefani $\mathrm{E}^{3}$ and Deneo-Pellegrini $\mathrm{H}^{3}$

\begin{abstract}
${ }^{1}$ Depto. De Epidemiología, Facultad de Medicina, IUCLAEH, Prado and Salt Lake P.16, Maldonado 20100, Uruguay
2Instituto de Radiología y Centro de Lucha Contra el Cáncer, Centro Hospitalario Pereira Rossell, Br. Artigas 1550, Montevideo 11300, Uruguay

${ }^{3}$ Grupo de Epidemiología, Depto. De Patología, Hospital de Clínicas, Facultad de Medicina (UDELAR), Av. Italia s/n y Las Heras, Montevideo 11300 , Uruguay
\end{abstract}

\begin{abstract}
In order to analyze detailed anthropometric characterisation for risk of breast cancer (BC) in premenopausal Uruguayan women, a case-control study was carried out at the Pereira Rossell Women's Hospital, Montevideo, where 253 incident BC cases and 497 frequency-matched healthy controls were interviewed on menstrual and reproductive story, and a series of body measurements were performed to calculate body composition and somatotype. Odds ratio (OR's) coefficients were taken as estimates of relative risk derived from unconditional logistic regression. Results show a positive association for the fat fraction (OR for highest quartile = 4.19, 95\% CI (95\% Confidence Interval) 2.70-6.50) as well as for the fat-to-muscle ratio (OR=4.68, 95\% CI 2.98-7.36). Muscle fraction was inversely associated with risk (OR=0.53 95\% CI 0.36-0.78). High endomorphism was the only somatotype variable associated to the disease risk (OR=1.69, 95\% CI 1.13-2.54), however, losing its association when fat amount was included in the regression model. Stratified analyses by body mass index (BMI) levels, bone weight, age groups and number of live births also showed risk increases for the highest fat fractions, displaying significant linear trends. Albeit most of the literature reports a putative slight protective effect for a high BMI in premenopausal women, our results suggest that fat fraction, amount and distribution might play a role as predisposing factors for premenopausal BC.
\end{abstract}

Keywords: anthropometry; body composition; breast cancer; epidemiology; fat; muscle; nutrition; risk factors; somatotype

\section{Introduction}

Anthropometric measures are considered to be linked with risk of breast cancer (BC). In the last years the association between body mass index (BMI) and BC was systematically examined in expert evaluations [1, 2]. Most studies show a contrast: heavier women have been found to be at increased risk of postmenopausal BC, whereas $\mathrm{BMI}$ is inversely associated with the risk of cancer among premenopausal women [3-5].

Obesity is associated with dysmetabolism and endangers the healthy balance of sexual hormone-production and regular menstrual cycles in women. An upper or central distribution of body fat is associated to multiple metabolic and hormonal changes, including insulin resistance, hyperinsulinism, a reduction in SHBG (sexual hormone binding globulins) levels, increase in the androgens and increase of aromatization [6, 7]. The inverse association between BMI and premenopausal BC has been attributed to more frequent anovulation in obese women [8].

The hormone adiponectin is secreted mostly from visceral adipose tissue and, contrary to leptin, is inversely associated with adiposity, hyperinsulinemia, and inflammation [9]. Moreover, adiponectin may exert anticancer effects by decreasing insulin/insulin-like growth factor (IGF)-1 and mTOR signaling via activation of 5'AMP-activated protein kinase (AMPK) and exerting anti-inflammatory actions via the inhibition of nuclear factor kappa-B (NF- $\kappa$ B) [9].

Besides, absence of association in premenopausal women was described for certain anthropometric measures (body size, BMI, fat distribution) in some populations, such

*Corresponding author: Ronco AL, Convención 1490 dep.202, 11100
Montevideo, Uruguay, E-mail: alronco@gmail.com

Received 14 November 2012 Revised 29 January 2013 Accepted 6 February 2013 Published 13 February 2013

Citation: Ronco AL, De Stefani E, Deneo-Pellegrini H (2013) Body composition, somatotype and risk of premenopausal breast cancer: a case-control study in Uruguay. J Cancer Res Ther 1: 77-86. doi:10.14312/2052-4994.2013-12

Copyright: (C) 2013 Ronco AL, et al. This is an open-access article distributed under the terms of the Creative Commons Attribution License, which permits unrestricted use, distribution and reproduction in any medium, provided the original author and source are credited. 
as Chinese [10,11], Japanese [12] or African-American women [13], unlike what has been consistently described in Western and Caucasian populations. Few years ago, waist-to-hip ratio was also associated with an increase of risk in premenopausal Nigerian [14] and Asian-American women [15]. Hence, the results are somehow inconsistent. Some researchers believe that BMI $>30$ may increase the risk of $\mathrm{BC}$ both in pre and postmenopausal periods [1619]. A recent meta-analysis performed on 15 cohort and 35 case-control studies showed that BMI can decrease the risk of $\mathrm{BC}$ by 0.07 although the association was not statistically significant [20] and it cannot be stated that $\mathrm{BMI}$ is a protective factor against the disease.

Research on body composition has been mainly focused on body fat estimation, according to methodologic studies that assessed anthropometric measures [21, 22]. Nevertheless, there is also interest in muscle mass due to its relationship with numerous aspects of human health, e.g. temperature regulation [23] and immune capability [24]. Reduction of muscle mass is a phenomenon observed with aging, but it is reinforced in sedentary lifestyles, which lead to a muscular loss and which can have deleterious effects on health [25].

McTiernan [26] suggested the usefulness of case-control studies on anthropometric factors in racial and ethnic minorities since these groups have been not sufficiently studied to date. Such studies can provide information of potential biologic importance concerning their link to risk factors and markers, as well as to the hormonal and metabolic mechanisms underlying the associations of anthropometric factors and BC [27]. Besides, according to international publications Uruguay is a country with a very high incidence of $\mathrm{BC}$ [28]. This fact involves inhabitants who have a trihybrid populational pattern comprised of Latin European (between 65 and 90\% of the genetic contribution), Amerindian and Black-African origin, according to anthropologic-genetic studies [29].

In the last twenty years, the disease risk among Uruguayan women has been thoroughly studied from the nutritional viewpoint, not only focusing on diet but also on the anthropometric associations [30]. Concerning anthropometry, we have recently reported possible roles of somatotype and risk of $\mathrm{BC}$, which were related to a positive association for high endomorphism among premenopausal women but not in postmenopausal ones [31]. On the contrary, the study on body composition reported that fat fraction, muscle fraction and their ratio had associations regarding the risk of $\mathrm{BC}$ [32], but the study did not analyze by menopausal status.

In our opinion, body composition and its possible relationship with BC deserve a detailed analysis of its components. Taking into account the feasibility for such epidemiologic research in Uruguay and the need to clarify a possible role in premenopausal women, we decided to perform the present study in order to explore the role of body composition and somatotype for risk of BC in a premenopausal subset of the Uruguayan population. Preliminary results were recently communicated within an international event [33].

\section{Subjects and methods}

A hospital-based case-control study was carried out during the period between June/2004 and December/2010 at the Unit of Radiology and Oncology, located at the Pereira Rossell Women's Hospital in Montevideo. The quoted Unit at our Hospital admits women coming from all the country, in order to perform diagnostic mammograms and ultrasonograms in a predominantly asymptomatic population. Mammograms in the public health system are cost-free for women. Between the years 1993-2008 there has been an intensive educational activity through mass media for preventive purposes and also adult women can receive regular check-ups at their own will or through the prescription of specialists.

During the study period and after excluding the postmenopausal cases of BC for the study purposes, 253 incident cases of primary malignant $\mathrm{BC}$ were identified in the consulting population and enrolled into the study. Cytology was performed on biopsies of breast tissue obtained from patients who were classified as BI-RADS categories 4 (suspicious of malignancy) and 5 (positive diagnosis of cancer) $[34,35]$ on the basis of their mammogram. Since BC cases were interviewed and measured very early, they have not experienced any postdiagnostic or treatment-induced weight change. Although women did not participate formally in a screening program, cancers were usually diagnosed at early stages (ca. 8-10\% carcinoma in situ).

In the same time period and in the same institution, 505 healthy women with a negative diagnostic mammogram (BI-RADS categories 1-2 (completely negative, only with findings not associated with pathology, e.g. benign calcifications and/or axillary lymphnodes)) [36] performed the same day of the interview, were randomly selected as controls. They were frequency-matched by age ( \pm 5 years) to cases, being mandatory requirements for the controls not to be hospitalized at the moment of the interview and not being afflicted by a cancer. Most women under 30 were examined only with ultrasonography, unless findings also required a mammogram due to the high density of breasts at those ages. Normal older controls (ages $>60$ ) were relatively infrequent in consulting at the Unit and it was difficult to find completely normal mammograms in those women. After excluding 8 women who rejected the interview, a final number of 497 controls were recruited (response rate $>98 \%$ ). Therefore, 750 women consulting for a mammogram at our center were included in the study. Interviews and measurements were performed by an only nurse, who was blinded regarding the objectives of the study, as well as being previously trained and periodically supervised during the study period. All interviews were conducted in the hospital 
and performed face to face, and a written consent was obtained from every interviewed subject. The research was approved by the ethical committee of the Hospital.

A structured interview was used to assess the following areas: (1) Socio-demographic variables; (2) Menstrual and reproductive events (age at menarche, age at first live birth, number of children, months of breastfeeding, menopausal status [pre/post]). (3) History of cancer in first and second degree relatives; (4) Frequency, duration and intensity of physical exercise; (5) Self-reported weight at age 18; (6) A short food frequency questionnaire; (7) Queries on personal medical history. The latter two items will not be analyzed in the present study since a recent paper focused on them [37]. Menopausal status was defined a priori: if according to the subject (aged $>=45$ years) menstruations have ceased at least for six months having excluded pregnancy, she was classified as postmenopausal. Our inclusion criterion was more restrictive than the standard one (no menses for 1 year), as an attempt to avoid entering possible undesirable cases of early postmenopausal or perimenopausal women. Exercise was queried on activities out of the job time, even recreational or competitive, 5 years prior the interview. This assessment, whose method was not validated, was performed only as an exploratory tool in the studied group, whose restricted incomes limit their time and access to sport institutions. Respondents were not asked about hormonal replacement therapy since it is not usually prescribed to postmenopausal women who belong to the studied subpopulation. The hormonal receptors' status was not among the variables initially examined in this study.

\section{Anthropometric data}

\section{Measurements}

The following anthropometric measures were taken: height (measured to the nearest centimeter), weight (at intervals of $0.100 \mathrm{~kg}$ ), circumferences (in $\mathrm{cm}$ ): waist, hip, calf, relaxed arm, tensed arm; skinfolds (in mm): tricipital, subscapular, abdominal, supraspinal, iliac, mid-axillary, bicipital, mid-thigh, calf; and diameters (in $\mathrm{mm}$ ): bistiloid (wrist), bicondyleal (elbow), bicondyleal (femur).

Anthropometric equipment included: (1) a height scale and headboard; (2) a weighing scale which was used along the whole study period with a weekly calibration; (3) a vernier caliper, for measurement of diameters; (4) a flexible plastic tape at intervals of $0.5 \mathrm{~cm}$, for measurement of circumferences; and (5) a digital caliper FatTrack Pro® (AccuFitness, Greenwood Village, CO, USA), for skinfold measurements. If two consecutive measurements were similar, the obtained value was registered as valid. If both were different $( \pm 1 \mathrm{~mm}$ for skinfolds and diameters, \pm $0.5 \mathrm{~cm}$ for circumferences) a third one was taken and the median value was then registered. Subjects were weighed wearing minimal clothing. Measurements were performed according to Carter's instruction manual [38].

\section{Body composition}

Anthropometric data were used to quantify body size and body proportions. The following body measures were determined:

Body Mass Index = Weight $/$ Height2 (Quetelet's Index) Fat fraction $(\%)=($ subescapular + tricipital + supraspinal +abdominal skinfolds in $\mathrm{mm}$ ) x $0.153+5.783$

Bone fraction $(\%)=3.02 \times$ (height $2 \times$ bistiloid diameter in $\mathrm{m} x$ bicondyleal femoral diameter in $\mathrm{m})^{0.712}$

Muscle fraction $(\%)=100.0 \%-($ fat $\%+$ bone $\%+$ residual $\%)$

Residual fraction (\%) $=20.9 \%$ (preestablished for women)

Fat weight $=$ Total weight $\mathrm{x}$ (Fat fraction/100)

Muscle weight $=$ Total weight $\mathrm{x}$ (Muscle fraction /100)

Fat-to-muscle ratio (FMR) = Fat fraction/ Muscle fraction

Calculations of body measures were based on the Faulkner protocol [39], according to the anatomic four compartments method of De Rose [40]. This widely known author worked mainly on Brazilian people, who are an important populational reference for South American neighbours like Uruguayans. Albeit a published validation was not available, it belongs to a recognized group of other methods which have been developed with the aim of calculating body composition [41-43]. The same methodology was followed in our study on body composition [32].

\section{Somatotype}

A somatotype (ST) is "a quantitative description of the present shape and composition of the human body" [44]. This method of physique classification was developed by W.H. Sheldon in the first half of the past century [45] and further refined [46]. A ST describes the human physique as a whole, which is broken down into three components, which are always presented and read in this order: (1) endomorphy (2) mesomorphy (3) ectomorphy. These components differ between populations according to origins, age and sex. The changes that occur in a ST happen during childhood to maturity. However, STs can be altered through training and/or nutrition. An endomorphic ST characterizes the relative fatness of a person's body. The mesomorphic ST is characterized by musculo-skeletal size. Ectomorphy is characterized by relative linearity or slenderness and is derived from ponderal index (height in $\mathrm{cm}$ divided the cube root of weight in $\mathrm{kg}$ ).

Initially, everyone's body shape was described by three numbers from 1 to 7 , one for each of the three basic STs, although longer scales are currently also used. Dominant ST of a subject is defined as a ST component rating at least 0.5 points higher than either of the other two component ratings. Ratings on each component up to 2.5 are considered low, 3 to 5 are moderate, 5.5 to 7 are high, and 7.5 and above are very high [44]. The highest value leads to the labeling of an individual, according to this prevailing component. The rating is phenotypical, 
based on the concept of geometrical size-dissociation and applicable to both genders from childhood to old age.

Calculations of ST for each patient were made with the specialized software Somatotype ${ }^{\circledR}$ (Release 1.0, Sweat Technologies, Australia, 2001). For such calculations, the following measurements were taken into account: height, weight, four skinfolds (triceps, subscapular, supraspinal, and mid-calf), two circumferences (tensed arm, calf) and two bone breadths (humerus, femur). Mean values of ST were calculated for all cases and all controls. Formulas applied to calculate ST, also according to Carter's instruction manual [38] are the following:

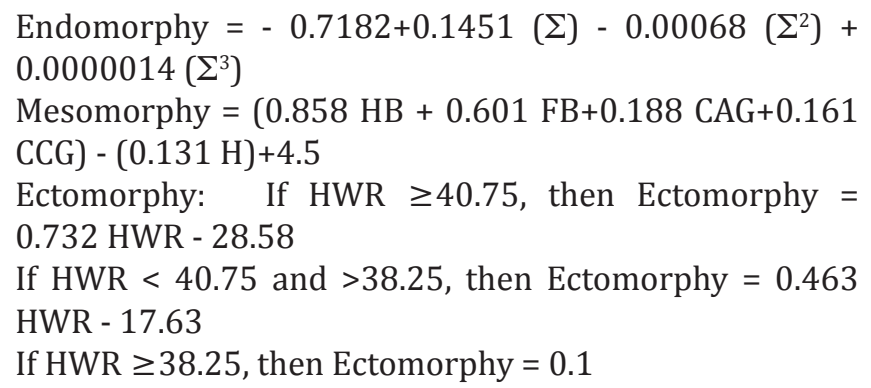

Where: $\Sigma=$ (sum of triceps, subscapular and supraspinale skinfolds) multiplied by $(170.18 /$ height in $\mathrm{cm}) ; \mathrm{HB}=$ humerus breadth; $\mathrm{FB}=$ femur breadth; $\mathrm{CAG}=$ corrected arm girth; $\mathrm{CCG}=$ corrected calf girth; $\mathrm{H}=$ height; $\mathrm{HWR}=$ height / cube root of weight.

CAG and CCG are the girths corrected for the triceps or calf skinfolds respectively as follows: $\mathrm{CAG}=$ flexed arm girth - triceps skinfold $/ 10 ; \mathrm{CCG}=$ maximal calf girth - calf skinfold/10.

\section{Statistical analysis}

We calculated mean values \pm standard deviation of the studied variables, as well as correlations among body measures. Adjusted odds ratios (ORs) and 95\% confidence intervals (CI)s for each variable were calculated by unconditional logistic regression [47]. Potential confounders were included in the multivariate analysis. Equations included terms for age, urban/rural status, family history of $\mathrm{BC}$ in $1^{\circ}$ and $2^{\circ}$ degree relatives, family history of other cancers in $1^{\circ}$ degree relatives, age at menarche, age at first live birth, years between menarche and first pregnancy, number of live births, months of breastfeeding, oral contraception and BMI. All the calculations were performed with the software STATA (version 10, College Station, Texas, USA 2007).

\section{Results and discussion}

Table 1 displays the general features of the study population. Taking into account some lack of controls with ages $>60$ when data entry was finished for this analysis, a very homogeneous population is described. Socio-demographic and lifestyle variables were very similar whereas menstrual and reproductive variables displayed some differences related to the age at first live birth, number of live births and number of months of breastfeeding.

Mean values of the anthropometric parameters are presented in Table 2. Significant differences between cases and controls were found for most skinfold thickness parameters. Fat weight and fraction (\%), muscle weight and fraction (\%) and fat/muscle ratio displayed also significant differences.

Adjusted OR's of BMI, fat fraction, muscle fraction, FMR and Endomorphy are presented in Table 3. BMI was found to be not associated with risk of BC. Fat fraction, FMR and Endomorphy displayed significant positive associations, with significant linear trends. Muscle fraction, on the contrary, was inversely and significantly associated with the risk of $\mathrm{BC}$. When a term for Muscle weight was included in the model, the estimates for Endomorphy were almost similar to those obtained in its previous model. Nevertheless, the inclusion of a term for fat weight led the associations to the null.

Table 4 displays adjusted OR's of fat and muscle fraction stratified by selected variables (e.g., age group, BMI). In all strata of these variables the OR's of fat fraction were significantly increased for the highest tertile. The estimates displayed a significant trend in all cases. The OR's of muscle fraction were significantly reduced in almost strata, usually with significant trends too.

Table 5 displays adjusted OR's of Fat/Muscle Ratio stratified by the same selected variables. In all strata of these variables the OR's of FMR were significantly increased for the highest tertile. The estimates showed also a significant trend in all cases, reproducing a similar behavior than fat fraction.

Our results show that while the fat fraction and the Fat/ Muscle Ratio were positively associated with the risk of $\mathrm{BC}$, the muscle fraction was inversely associated with this risk in the analyzed population. Besides, the analysis of Somatotype revealed that cases were more endomorphic than controls did: a high endomorphy (rather similar to the distribution of the gynoid-type obesity) was found as positively associated to the risk of BC. Regarding this, a higher aromatase activity was described 25 years ago in these body regions [48] and it could be a plausible explanation for our current findings, although we accept that the association could be stronger among postmenopausal women.

In addition, mean values of $90 \mathrm{~cm}$ for waist and $100 \mathrm{~cm}$ for hip circumferences suggest the existence of central-type obesity in the studied population, which would lead then to a mixed pattern of adiposity distribution when the high endomorphy is combined with the latter. Nevertheless, when the regression model included fat weight, the positive association of endomorphy disappeared, tending 
Table 1 Socio-demographic, family history of cancer and menstrual-reproductive features of the studied population

\begin{tabular}{|c|c|c|c|c|c|c|c|}
\hline \multirow{2}{*}{ Variable } & \multicolumn{3}{|c|}{ Controls } & \multicolumn{4}{|c|}{ Cases } \\
\hline & Categories & Number & $\%$ & Number & $\%$ & Global p-value & Trend \\
\hline \multirow[t]{6}{*}{ Age (years) } & $<30$ & 28 & 5.6 & 12 & 4.7 & & \\
\hline & $30-34$ & 49 & 9.9 & 23 & 9.1 & & \\
\hline & $35-39$ & 99 & 19.9 & 42 & 16.6 & & \\
\hline & $40-44$ & 148 & 29.8 & 62 & 24.5 & & \\
\hline & $45-49$ & 132 & 26.6 & 88 & 34.8 & & \\
\hline & $>=50$ & 41 & 8.2 & 26 & 10.3 & 0.18 & 0.05 \\
\hline \multirow[t]{3}{*}{ Education } & $<=6$ & 194 & 39.0 & 98 & 38.7 & & \\
\hline & $7-12$ & 250 & 50.3 & 135 & 53.4 & & \\
\hline & $>=13$ & 53 & 10.7 & 20 & 7.9 & 0.44 & 0.61 \\
\hline Urban/rural & Urban & 488 & 98.2 & 247 & 97.6 & & \\
\hline Status & Rural & 9 & 1.8 & 6 & 2.4 & 0.60 & \\
\hline \multirow[t]{4}{*}{ Age at menarche } & $<=11$ & 121 & 24.3 & 53 & 20.9 & & \\
\hline & 12 & 124 & 24.9 & 69 & 27.3 & & \\
\hline & 13 & 124 & 24.9 & 70 & 27.7 & & \\
\hline & $>=14$ & 128 & 25.8 & 61 & 24.1 & 0.60 & 0.74 \\
\hline $\mathrm{N}^{\circ}$ of live & Nulliparae & 36 & 7.2 & 20 & 7.9 & & \\
\hline \multirow[t]{2}{*}{ Births } & $1-2$ & 242 & 48.7 & 121 & 47.8 & & \\
\hline & $>=3$ & 219 & 44.1 & 112 & 44.3 & 0.94 & 0.92 \\
\hline Age at first & Nulliparae & 36 & 7.2 & 20 & 7.9 & & \\
\hline \multirow[t]{3}{*}{ Delivery } & $<=19$ & 187 & 37.6 & 75 & 29.6 & & \\
\hline & $20-23$ & 150 & 30.2 & 66 & 26.1 & & \\
\hline & $>=24$ & 124 & 24.9 & 92 & 36.4 & 0.008 & 0.01 \\
\hline Time menarche & $<=6$ & 171 & 37.1 & 67 & 28.8 & & \\
\hline \multirow[t]{2}{*}{ first delivery (years) } & $7-11$ & 165 & 35.8 & 76 & 32.6 & & \\
\hline & $>=12$ & 125 & 27.1 & 90 & 38.6 & 0.006 & 0.002 \\
\hline Breastfeeding & No & 57 & 11.5 & 34 & 13.4 & & \\
\hline \multirow[t]{2}{*}{ (months) } & $1-16$ & 216 & 43.5 & 113 & 44.7 & & \\
\hline & $>=17$ & 224 & 45.1 & 106 & 41.9 & 0.61 & 0.33 \\
\hline \multirow[t]{2}{*}{ Oral contracept. } & No & 173 & 34.8 & 76 & 30.3 & & \\
\hline & Yes & 324 & 65.2 & 175 & 69.7 & 0.21 & \\
\hline \multirow[t]{2}{*}{ Exercise (leisure) } & No & 289 & 58.1 & 150 & 59.3 & & \\
\hline & Yes & 208 & 41.9 & 103 & 40.7 & 0.81 & \\
\hline Breast cancer & No & 461 & 92.8 & 216 & 85.4 & & \\
\hline in $1^{\circ}$ degree & Yes & 36 & 7.2 & 37 & 14.6 & 0.001 & \\
\hline Breast cancer & No & 382 & 76.9 & 200 & 79.1 & & \\
\hline \multirow[t]{2}{*}{ in $2^{\circ}$ degree } & 1 & 91 & 18.3 & 35 & 13.8 & & \\
\hline & $>=2$ & 24 & 4.8 & 18 & 7.1 & 0.16 & 0.98 \\
\hline Other cancers & No & 339 & 68.2 & 163 & 64.4 & & \\
\hline in $1^{\circ}$ degree & Yes & 158 & 31.8 & 90 & 35.6 & 0.30 & \\
\hline Total patients & & 497 & 100.0 & 253 & 100.0 & & \\
\hline
\end{tabular}


Table 2 Mean values of the anthropometric measurements and derived calculations $(\mathrm{n}=750)$

\begin{tabular}{|c|c|c|c|c|}
\hline Groups & Variables & $\begin{array}{l}\text { Controls } \\
\text { Mean } \pm S D\end{array}$ & $\begin{array}{l}\text { Cases } \\
\text { Mean } \pm S D\end{array}$ & P-value \\
\hline & Height $(\mathrm{cm})$ & $159.77 \pm 5.94$ & $159.47 \pm 5.98$ & 0.52 \\
\hline & Weight (kg) & $67.89 \pm 12.79$ & $68.29 \pm 15.58$ & 0.70 \\
\hline & Weight at age 18 (kg) & $55.16 \pm 9.09$ & $54.81 \pm 9.18$ & 0.62 \\
\hline \multirow[t]{6}{*}{ Circumferences $(\mathrm{cm})$} & Waist & $89.76 \pm 11.34$ & $90.05 \pm 13.77$ & 0.76 \\
\hline & Hip & $100.55 \pm 10.27$ & $100.50 \pm 14.17$ & 0.96 \\
\hline & Forearm & $25.53 \pm 1.96$ & $25.84 \pm 2.59$ & 0.08 \\
\hline & Arm (relaxed) & $28.72 \pm 3.17$ & $29.08 \pm 4.19$ & 0.19 \\
\hline & Arm (tensed) & $31.45 \pm 3.42$ & $31.53 \pm 4.39$ & 0.79 \\
\hline & Calf & $37.30 \pm 5.29$ & $37.16 \pm 4.07$ & 0.72 \\
\hline \multirow[t]{3}{*}{ Diameters (mm) } & Bistiloid (wrist) & $49.31 \pm 3.05$ & $50.02 \pm 3.33$ & 0.005 \\
\hline & Bicondyleal (elbow) & $60.57 \pm 4.46$ & $61.41 \pm 5.35$ & 0.03 \\
\hline & Bicondyleal (knee) & $88.37 \pm 8.27$ & $88.72 \pm 8.63$ & 0.60 \\
\hline \multirow[t]{9}{*}{ Skinfolds (mm) } & Tricipital & $24.92 \pm 9.47$ & $28.84 \pm 11.31$ & $<0.0001$ \\
\hline & Bicipital & $11.32 \pm 5.51$ & $15.10 \pm 7.44$ & $<0.0001$ \\
\hline & Subscapular & $26.07 \pm 10.90$ & $28.78 \pm 13.79$ & 0.005 \\
\hline & Abdominal & $46.08 \pm 18.58$ & $47.32 \pm 19.53$ & 0.42 \\
\hline & Mid-axillary & $23.62 \pm 11.04$ & $28.11 \pm 14.95$ & $<0.0001$ \\
\hline & Supraspinal & $19.91 \pm 9.23$ & $22.56 \pm 11.10$ & 0.0009 \\
\hline & Iliac & $48.49 \pm 18.73$ & $53.74 \pm 20.25$ & 0.0008 \\
\hline & Mid-thigh & $41.67 \pm 15.39$ & $41.94 \pm 18.13$ & 0.84 \\
\hline & Calf & $31.73 \pm 9.44$ & $36.77 \pm 11.99$ & $<0.0001$ \\
\hline \multirow[t]{12}{*}{ Calculations } & B.M.I. (kg/m2) & $26.60 \pm 4.86$ & $26.85 \pm 5.98$ & 0.55 \\
\hline & B.M.I. at age $18(\mathrm{~kg} / \mathrm{m} 2)$ & $21.61 \pm 3.40$ & $21.57 \pm 3.45$ & 0.85 \\
\hline & Fat weight (kg) & $26.97 \pm 7.90$ & $29.37 \pm 8.62$ & 0.0003 \\
\hline & Fat fraction (\%) & $39.66 \pm 8.94$ & $43.17 \pm 8.25$ & $<0.0001$ \\
\hline & Muscle weight (kg) & $18.03 \pm 7.20$ & $15.59 \pm 7.12$ & $<0.0001$ \\
\hline & Muscle fraction (\%) & $26.37 \pm 8.78$ & $22.62 \pm 7.97$ & $<0.0001$ \\
\hline & Bone weight $(\mathrm{kg})$ & $8.71 \pm 1.05$ & $8.53 \pm 1.38$ & 0.005 \\
\hline & Bone fraction (\%) & $13.10 \pm 1.89$ & $12.92 \pm 2.41$ & 0.27 \\
\hline & Fat/muscle Ratio & $1.94 \pm 1.56$ & $2.47 \pm 1.83$ & 0.0001 \\
\hline & Endomorphy (score) & $6.41 \pm 1.86$ & $6.92 \pm 2.13$ & 0.001 \\
\hline & Mesomorphy (score) & $5.03 \pm 1.62$ & $5.05 \pm 1.95$ & 0.93 \\
\hline & Ectomorphy (score) & $1.00 \pm 1.03$ & $1.10 \pm 1.15$ & 0.23 \\
\hline
\end{tabular}

$\mathrm{SD}=$ standard deviation 
Table 3 Odds ratios of breast cancer for selected calculated anthropometric variables

\begin{tabular}{|c|c|c|c|c|c|}
\hline \multirow{3}{*}{ Variable } & \multicolumn{5}{|c|}{ Tertiles of exposure } \\
\hline & & $I$ & II & III & Trend \\
\hline & & OR $(95 \% C I)$ & OR $(95 \% C I)$ & OR $(95 \% C I)$ & $P$-value \\
\hline Fat weight (kg) & 1.00 & ref. & $1.67(1.10-2.57)$ & $2.70(1.79-4.08)$ & $<0.0001$ \\
\hline Fat fraction (\%) & 1.00 & ref. & $2.27(1.43-3.60)$ & $4.19(2.70-6.50)$ & $<0.0001$ \\
\hline Muscle weight (kg) & 1.00 & ref. & $0.50(0.34-0.75)$ & $0.70(0.48-1.02)$ & 0.06 \\
\hline Muscle fraction (\%) & 1.00 & ref. & $0.62(0.43-0.90)$ & $0.53(0.36-0.78)$ & 0.001 \\
\hline Bone weight (kg) & 1.00 & ref. & $0.89(0.61-1.31)$ & $1.08(0.74-1.56)$ & 0.71 \\
\hline Bone fraction (\%) & 1.00 & ref. & $0.64(0.43-0.95)$ & $0.92(0.63-1.34)$ & 0.67 \\
\hline Fat/muscle ratio & 1.00 & ref. & $2.52(1.57-4.04)$ & $4.68(2.98-7.36)$ & $<0.0001$ \\
\hline Endomorphy (score) & 1.00 & ref. & $1.10(0.72-1.69)$ & $1.69(1.13-2.54)$ & 0.009 \\
\hline Endomorphy * (score) & 1.00 & ref. & $0.81(0.50-1.32)$ & $0.80(0.41-1.57)$ & 0.51 \\
\hline Endomorphy** (score) & 1.00 & ref. & $1.10(0.72-1.70)$ & $1.79(1.19-2.70)$ & 0.005 \\
\hline
\end{tabular}

Regression model including: age (categorical), age at menarche (categorical), number of live births (categorical), age at first delivery (categorical), years between menarche and first delivery (categorical), breastfeeding (categorical), oral contraception (yes/no), family history of breast cancer in 1st degree (yes/no), family history of breast cancer in 2nd degree (yes/no) and family history of other cancers in 1st degree (yes/no).

* Regression model including a term for fat weight (continuous)

** Regression model including a term for muscle weight (continuous)

Table 4 Odds Ratios of breast cancer for fat and muscle fraction, stratified by selected variables

\begin{tabular}{|c|c|c|c|c|c|c|c|}
\hline \multirow{3}{*}{ Variable } & \multicolumn{4}{|c|}{ Tertiles of fat fraction } & \multicolumn{3}{|c|}{ Tertiles of muscle fraction } \\
\hline & \multirow{2}{*}{ Categories } & $I I$ & III & Trend & II & III & Trend \\
\hline & & OR $(95 \% C I)$ & OR $(95 \% C I)$ & P-value & OR $(95 \% C I)$ & OR $(95 \% C I)$ & $P$-value \\
\hline \multirow[t]{3}{*}{ Age groups (years) } & $<35$ & $1.79(0.42-7.54)$ & $4.18(1.09-16.0)$ & 0.025 & $0.38(0.12-1.20)$ & $0.37(0.11-1.29)$ & 0.07 \\
\hline & $35-44$ & $1.92(0.98-3.78)$ & $3.26(1.69-6.28)$ & $<0.0001$ & $0.71(0.40-1.24)$ & $0.51(0.28-0.95)$ & 0.03 \\
\hline & $>44$ & $3.30(1.52-7.16)$ & $6.24(3.00-12.9)$ & $<0.0001$ & $0.63(0.34-1.18)$ & $0.55(0.30-1.00)$ & 0.05 \\
\hline \multirow[t]{2}{*}{$\begin{array}{l}\text { Number of live } \\
\text { births }\end{array}$} & $<=2$ & $2.23(1.13-4.05)$ & $3.25(1.83-5.80)$ & $<0.0001$ & $0.71(0.44-1.17)$ & $0.60(0.35-1.03)$ & 0.06 \\
\hline & $>=3$ & $2.48(1.15-4.05)$ & $6.71(3.23-13.9)$ & $<0.0001$ & $0.48(0.26-0.88)$ & $0.42(0.23-0.75)$ & 0.003 \\
\hline \multirow[t]{2}{*}{$\begin{array}{l}\text { Body mass index } \\
\text { at age } 18(\mathrm{~kg} / \mathrm{m} 2)\end{array}$} & $<25$ & $2.08(1.26-3.45)$ & $4.26(2.66-6.84)$ & $<0.0001$ & $0.53(0.35-0.77)$ & $0.58(0.38-0.87)$ & 0.005 \\
\hline & $>=25$ & $5.54(1.41-21.8)$ & $6.06(1.42-25.9)$ & 0.015 & $1.63(0.46-5.80)$ & $0.19(0.05-0.81)$ & 0.02 \\
\hline \multirow[t]{3}{*}{ Bone weight (kg) } & $<=8.24$ & $0.96(0.40-2.28)$ & $3.41(1.66-7.03)$ & $<0.0001$ & $0.26(0.12-0.58)$ & $0.81(0.44-1.50)$ & 0.34 \\
\hline & 8.24-9.08 & $4.27(1.57-11.6)$ & $5.11(1.92-13.6)$ & 0.002 & $0.60(0.32-1.15)$ & $0.17(0.06-0.49)$ & 0.001 \\
\hline & $>=9.09$ & $3.02(1.42-6.38)$ & $6.18(2.79-13.7)$ & $<0.0001$ & $0.90(0.43-1.86)$ & $0.45(0.21-0.94)$ & 0.02 \\
\hline \multirow[t]{2}{*}{ Endomorphy (score) } & $<6.7$ & $1.65(0.93-2.95)$ & $2.36(1.27-4.39)$ & 0.006 & $0.56(0.31-1.01)$ & $0.31(0.17-0.58)$ & $<0.0001$ \\
\hline & $>=6.7$ & $3.77(1.52-9.37)$ & $6.91(2.89-16.5)$ & $<0.0001$ & $0.69(0.42-1.14)$ & $1.04(0.61-1.78)$ & 0.90 \\
\hline
\end{tabular}

Regression model including: age (categorical), age at menarche (categorical), number of live births (categorical), age at first delivery (categorical), years between menarche and first delivery (categorical), breastfeeding (categorical), oral contraception (yes/no), family history of breast cancer in 1st degree (yes/no), family history of breast cancer in 2nd degree (yes/no) and family history of other cancers in 1st degree (yes/no).

The first tertile of each analyzed anthropometric variable, omitted in the Table, was the reference value with an OR=1.00. 
to the null, but the associations of adiposity still remained. When a term for muscle weight was included in the model, the estimates for endomorphy were almost similar to those obtained without its inclusion. Furthermore, the estimates of muscle weight and fraction lost their inverse association after the inclusion of a term for endomorphy

Table 5 Odds Ratios of breast cancer for fat/muscle ratio, stratified by selected variables

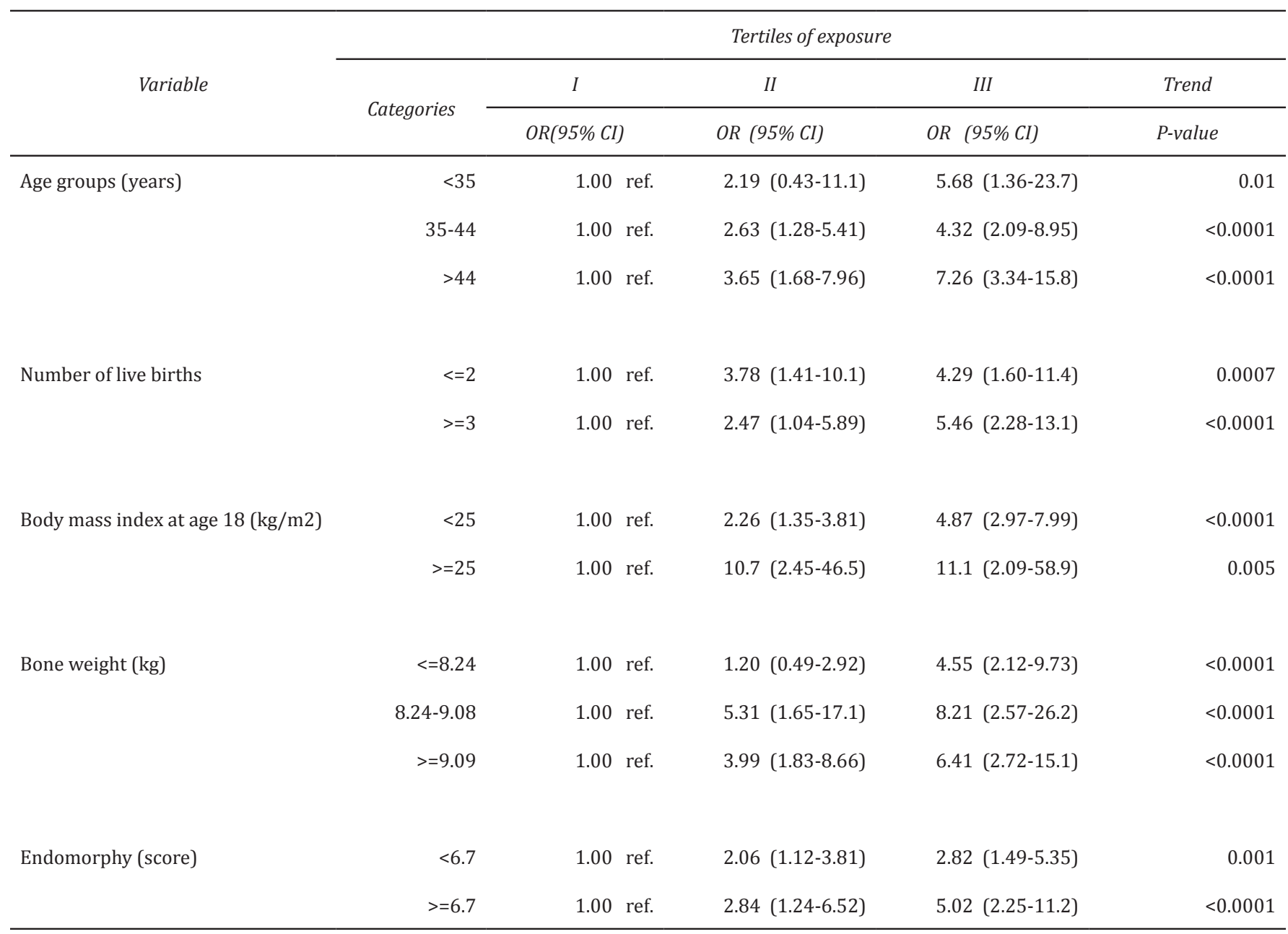

Regression model including: age (categorical), age at menarche (categorical), number of live births (categorical), age at first delivery (categorical), years between menarche and first delivery (categorical), breastfeeding (categorical), oral contraception (yes/no), family history of breast cancer in 1 st degree (yes/no), family history of breast cancer in 2nd degree (yes/no) and family history of other cancers in 1st degree (yes/no).

(results not shown). These facts remark, in our opinion, that probably adipose fraction and amount are more relevant to the risk of the disease than any other calculated anthropometric variable.

We have found that whereas BMI displayed strong correlations with both fat $(\mathrm{r}=0.74, \mathrm{p}<0.001)$ and muscle weight $(\mathrm{r}=0.49, \mathrm{p}<0.001)$, FMR showed strong correlations with their fat $(\mathrm{r}=0.89, \mathrm{p}<0.001)$ and muscle fractions $(r=-0.89, p<0.001)$ (results not shown). Increase of risk found for FMR suggests that both, fraction and amount of the original weight components might play a role as predisposing factors for BC. In this study population, BMI has not displayed the same protective association that characterized premenopausal women in American and European studies. On the other hand, the present study showed that BMI was almost similarly and highly correlated with fat and muscle weights, suggesting that muscle and fat effect cancelled out. However, high correlations of BMI with fat as well as with muscle weight turn reasonable to assume that a reduced $\mathrm{BC}$ risk of high BMI among premenopausal women belonging to other populations could be also due to a high muscular weight in the young women [49].

In support of our findings, we must cite two articles from the last decade $[50,51]$, which found a positive association between body composition in premenopausal women and the estrogen metabolites $2-\alpha \mathrm{OH}$ and $16-\alpha \mathrm{OH}$-estrone: while thicker skinfolds were associated with higher 16$\alpha \mathrm{OH}$ levels, an increase in lean body mass was associated with an improvement in $2 / 16-\alpha \mathrm{OH}$ estrogens ratio. Those studies confirmed what was hypothesized three decades before [52]. The 16- $\alpha \mathrm{OH}$ estrogen metabolites are believed to participate in the initiation process (they are genotoxic) as well in the promotion (enhancing cell proliferation) $[53,54]$. Although new evidence was added concerning postmenopausal women [55], very recent 
findings give additional support for our work, suggesting that premenopausal urinary 2:16 $\alpha-\mathrm{OH}$-estrone may play a role in breast carcinogenesis [56].

According to: (a) the similarity of OR estimates for FMR and fat percentage (4.68 vs. 4.10 resp.); (b) the strong positive correlation between them $(\mathrm{r}=.89, \mathrm{p}<0.001)$; and c) the strong negative correlation between fat and muscle fractions $(\mathrm{r}=-.97, \mathrm{p}<0.001)$, we cannot preclude the possibility that FMR could be a proxy of fat fraction. Besides, the controversy introduced by the findings of a positive association between fat-free mass and the risk of $\mathrm{BC}$ [7] since muscle mass and fat-free mass are not the same-leads to think that bone weight might play a role in such association, which deserves further investigation.

As other case-control studies, limitations and strengths should be recognized. Unavailability of validation of the applied anthropometric method for calculating body composition, despite its wide use at a regional level, is a limitation that we recognize. Since occupational activity was not registered in our study, we were able to analyze only exercise as a leisure activity. Albeit physical exercise has not shown differences between cases and controls, we cannot preclude the possibility that occupational or daily living activities are different between them. Since this information was not measured, we are not able to go further. Future studies should clarify the point.

On the other hand, both cases and controls belong to a very homogeneous base population. They belong to the same healthcare system, they were matched by age, and socio-demographic variables were mostly similar. Furthermore, family history of $\mathrm{BC}$ in first degree relatives and some other classical reproductive risk factors for BC showed significant differences. Women with normal mammograms -that is, not only cancer-free womenwere selected as controls, in order to reduce the possibility of biasing results due to an association of benign breast diseases with the analyzed anthropometric items. Our inclusion criterion for premenopausal patients, more restrictive than the standard one, with the aim of avoiding possible undesirable cases of early postmenopausal or perimenopausal women-, could have been potentially disadvantageous if a postmenopausal subset was to be selected, but we evaluated it as convenient for the analysis of the current premenopausal subgroup. Finally, a high participation was achieved making selection bias less likely. People affiliated to the public health system are prone to cooperate with surveys and studies, therefore a high participation is always expected.

\section{Conclusions}

We analysed measures of body composition and showed that a high fat fraction, a high FMR and a high endomorphy were significantly and positively associated to the risk of pre-menopausal BC independently of BMI level. Besides, the negative significant association of muscle fraction was lost when endomorphy was included in the multivariate analyses. In particular, endomorphy lost its statistical association when fat was included in the regression models, turning fat variables as the most relevant ones of the study. Our research is on-going and new analyses of a larger sample as well as of other women of different origins e.g. those belonging to the pre-paid system considered the local high-risk subpopulation-, are needed to confirm the results obtained so far.

\section{Funding}

No sponsors or any funding sources have supported the research. The anthropometric research has been approved by a Bioethics Committee of the Hospital where the study was carried out.

\section{Conflict of interest}

The authors disclose any financial or personal conflict of interest.

\section{References}

[1] World Cancer Research Fund/ American Institute for Cancer Research. (2007) Food, nutrition, physical activity, and the prevention of cancer: a Global Perspective. Washington DC: American Institute for Cancer Research.

[2] International Agency for Research on Cancer (2002) Weight control and physical activity. IARC Handbooks of Cancer Prevention. Lyon: IARC Press. Vol.6.

[3] Macinnis RJ, English DR, Gertig DM, Hopper JL, Giles GG (2004) Body size and composition and risk of postmenopausal breast cancer. Cancer Epidemiol Biomarkers Prev 13: 2117-2125.

[4] Lahmann PH, Hoffmann K, Allen N, van Gils CH, Khaw KT, et al. (2004) Body size and breast cancer risk: findings from the European Prospective Investigation into Cancer And Nutrition (EPIC). Int J Cancer 111: 762-771.

[5] Lahmann PH, Schulz M, Hoffmann K, Boeing H, Tjønneland A, et al. (2005) Long-term weight change and breast cancer risk: the European prospective investigation into cancer and nutrition (EPIC). Br J Cancer 93: 582-589.

[6] Bruning PF, Bonfrèr JM, van Noord PA, Hart AA, de Jong-Bakker M, et al. (1992) Insulin resistance and breast-cancer risk. Int J Cancer 52:511-516.

[7] Ballard-Barbash R (1994) Anthropometry and breast cancer. Body size--a moving target. Cancer 74:1090-1100.

[8] La Vecchia C, Decarli A, di Pietro S, Franceschi S, Negri E, et al. (1985) Menstrual cycle patterns and the risk of breast disease. Eur J Cancer Clin Oncol 21: 417-422.

[9] Dalamaga M, Diakopoulos KN, Mantzoros CS (2012) The role of adiponectin in cancer: a review of current evidence. Endocr Rev 33 : 547-594.

[10] Shu XO, Jin F, Dai Q, ShiJr, Potter JD, et al. (2001) Association of body size and fat distribution with risk of breast cancer among Chinese women. Int J Cancer 94: 449-455.

[11] Chow LW, Lui KL, Chan JC, Chan TC, Ho PK, et al. (2005) Association between body mass index and risk of formation of breast cancer in Chinese women. Asian J Surg 28: 179-184.

[12] Hirose K, Tajima K, Hamajima N, Takezaki T, Inoue M, et al. (2001) Association of family history and other risk factors with breast cancer risk among Japanese premenopausal and postmenopausal women. Cancer Causes Control 12: 349-358.

[13] Hall IJ, Newman B, Millikan RC, Moorman PG (2000) Body size and breast cancer risk in black women and white women: the Carolina Breast Cancer Study. Am J Epidemiol 151: 754-764.

[14] Okobia MN, Bunker CH, Zmuda JM, Osime U, Ezeome ER, et al. (2006) Anthropometry and breast cancer risk in Nigerian women. Breast J 12: 462-466. 
[15] Wu AH, Yu MC, Tseng CC, Pike MC (2007) Body size, hormone therapy and risk of breast cancer in Asian-American women. Int J Cancer 120: 844-852.

[16] Barlow WE, White E, Ballard-Barbash R, Vacek PM, Titus-Ernstoff L, et al. (2006) Prospective breast cancer risk prediction model for women undergoing screening mammography. J Natl Cancer Inst 98:1204-1214.

[17] Sonnenschein E, Toniolo P, Terry MB, Bruning PF, Kato I, et al. (1999) Body fat distribution and obesity in pre and postmenopausal breast cancer. Int J Epidemiol 28: 1026-1031.

[18] Tehard B, Clavel-Chapelon F (2006) Several anthropometric measurements and breast cancer risk: results of the E3N cohort study. Int J Obes (Lond) 30: 156-163.

[19] Tian YF, Chu CH, Wu MH, Chang CL, Yang T, et al. (2007) Anthropometric measures, plasma adiponectin, and breast cancer risk. Endocr Relat Cancer 14: 669-777.

[20] Cheraghi Z, Poorolajal J, Hashem T, Esmailnasab N, Doosti Irani A (2012) Effect of body mass index on breast cancer during premenopausal and postmenopausal periods: a meta-analysis. PLoS ONE 7(12): e51446.

[21] De Girolami DH (2003) Fundamentals of nutritional assessment and body composition. Buenos Aires, Ed. El Ateneo, (In Spanish).

[22] Berdasco Gómez A (2002) Assessment of nutritional status in the adult through anthropometry. Rev Cubana Aliment Nutr 16:146152 (in Spanish).

[23] Anderson GS (1999) Human morphology and temperature regulation. Int J Biometeorol 43: 99-109.

[24] Mariani E, Ravaglia G, Forti P, Meneghetti A, Tarozzi A, et al. (1999) Vitamin D, thyroid hormones and muscle mass influence natural killer $(\mathrm{NK})$ innate immunity in healthy nonagenarians and centenarians. Clin Exp Immunol 116:19-27.

[25] Marcell TJ (2003) Sarcopenia: causes, consequences, and preventions. J Gerontol A Biol Sci Med Sci 58:911-916.

[26] McTiernan A (2000) Associations between energy balance and body mass index and risk of breast carcinoma in women from diverse racial and ethnic backgrounds in the U.S. Cancer 88:1248-1255.

[27] Friedenreich CM (2001) Review of anthropometric factors and breast cancer risk. Eur J Cancer Prev 10: 15-32.

[28] Ferlay J, Shin HR, Bray F, Forman D, Mathers C, et al. (2010) Estimates of worldwide burden of cancer in 2008: GLOBOCAN 2008. Int J Cancer 127: 2893-2917.

[29] Sans M (2000) Admixture studies in Latin America: from the 20th to the 21st century. Hum Biol 72:155-177.

[30] Ronco AL, De Stéfani E (2011) Nutritional epidemiology of breast cancer. Springer Verlag, Dordrecht.

[31] Ronco AL, Mendoza B, Varas X, Jaumandreu S, De Stéfani E, et al. (2008) Somatotype and risk of breast cancer: a case-control study in Uruguay. Braz J Epidemiol 11(2):215-227.

[32] Ronco AL, Boeing H, De Stefani E, Schulz M, Schulze M, et al. (2009) A case-control study on fat-to-muscle ratio and risk of breast cancer. Nutr Cancer 61: 466-474.

[33] Ronco AL, De Stéfani E, Deneo-Pellegrini H (2012) Body composition, somatotype and risk of premenopausal breast cancer: a case-control study in Uruguay. Proceedings of the XVIIth World Congress of Breast Diseases, Salvador, Brazil.

[34] Varas X, Leborgne F, Leborgne JH (1992) Nonpalpable, probably benign lesions: role of follow-up mammography. Radiology 184: 409-414.

[35] Feig SA (1999) Role and evaluation of mammography and other imaging methods for breast cancer detection, diagnosis, and staging. Semin Nucl Med 29: 3-15.

[36] American College of Radiology (1998) Breast imaging reporting and data system (BI-RADS), 3rd ed. Reston, VA: American College of Radiology.

[37] Ronco AL, De Stefani E, Deneo-Pellegrini H (2012) Risk factors for premenopausal breast cancer: a case-control study in Uruguay. Asian Pac J Cancer Prev 13: 2879-2886.

[38] Carter JEL (2002) The Heath-Carter anthropometric somatotype Instruction Manual. Surrey, Canada: TeP and Rosscraft.

[39] Faulkner J (1968) Physiology of swimming and diving. In Falls H: Exercise Physiology. Baltimore: Academic Press.

[40] De Rose EH, Pigatto E, Celi R (1984) Kinanthropometry, physical education and sport training. Brasilia: SEED (in Portuguese).
[41] Jackson AS, Pollack ML (1985) Practical Assessment of body composition. Physician Sport Med 13:76-90.

[42] Heymsfield SB, Wang Z, Baumgartner RN, Ross R (1997) Human body composition: advances in models and methods. Annu Rev Nutr 17: 527-558.

[43] Lee RC, Wang Z, Heo M, Ross R, Janssen I, et al. (2000) Totalbody skeletal muscle mass: development and cross-validation of anthropometric prediction models. Am J Clin Nutr 72:796-803.

[44] Carter JEL, Heath BH (1990) Somatotyping: Development and applications. Cambridge: Cambridge University Press.

[45] Sheldon WH (1950) The somatotype, the morphophenotype and the morphogenotype. Cold Spring Harb Symp Quant Biol 15: 373382.

[46] Heath BH, Carter JE (1967) A modified somatotype method. Am J Phys Anthropol 27:57-74.

[47] Breslow NE, Day NE (1980) Statistical methods in cancer research, Volume 1 The analysis of case control studies. IARC scientific publications $\mathrm{N}^{\circ} 32$. Lyon: IARC.

[48] Killinger DW, Perel E, Daniilescu D, Kharlip L, Lindsay WR (1987) The relationship between aromatase activity and body fat distribution. Steroids 50: 61-72.

[49] Evans WJ, Campbell W (1993) Sarcopenia and age-related changes in body composition and functional capacity. J Nutr 123: 465-468.

[50] Campbell KL, Westerlind KC, Harber VJ, Friedenreich CM, Courneya KS (2005) Associations between aerobic fitness and estrogen metabolites in premenopausal women. Med Sci Sports Exerc 37:585-592.

[51] Campbell KL, Westerlind KC, Harber VJ, Bell GJ, Mackey JR, et al. (2007) Effects of aerobic exercise training on estrogen metabolism in premenopausal women: a randomized controlled trial. Cancer Epidemiol Biomarkers Prev 16:731.

[52] Fishman J, Boyar RM, Hellman L (1975) Influence of body weight on estradiol metabolism in young women. J Clin Endocrinol Metab 41: 989-991.

[53] Bradlow HL, Hershcopf RE, Fishman JF (1986) Oestradiol 16 alphahydroxylase: a risk marker for breast cancer. Cancer Surv 5:573583.

[54] Muti P, Bradlow HL, Micheli A, Krogh V, Freudenheim JL, etal. (2000) Estrogen metabolism and risk of breast cancer: a prospective study of the 2:16alpha-hydroxyestrone ratio in premenopausal and postmenopausal women. Epidemiology 11:635-640.

[55] Cauley JA, Zmuda JM, Danielson ME, Ljung BM, Bauer DC, et al. (2003) Estrogen metabolites and the risk of breast cancer in older women. Epidemiology 14:740-744.

[56] Dallal CM, Stone RA, Cauley JA, Ness RB, Vogel VG, et al. (2012) Urinary estrogen metabolites and breast cancer: a combined analysis of individual level data. Int J Biol Markers (in press) doi: 10.5301/JBM.2012.9353. 